W. G. Mixter 4, A. Sauer ${ }^{5}$ Marek $^{6}$, W. Grote and H. Krekeler ${ }^{7}$, and A. Schöberl ${ }^{8}$. The latter describes a micro-version. As a safeguard against explosion, C. N. Warren fills his combustion tube with asbestos, while Grote, Krekeler and Schöberl enclose the heated area within two sintered plates for the same reason. These precautions do not, however, alter the fact that contact materials are not used. One further variant by $H$. ter Meulen and J. Heslinga must be mentioned in this connexion. These analysts recommend the use of some quartz splinters in front of an unpacked heated area.

Dyson Perrins Laboratory,

F. B. Strrauss.

The University, Oxford. Aug. 28.

${ }^{1}$ Belcher, R., and Spooner, C. E., J. Chem. Soc., 313 (1943).

'Belcher, R., and Spooner, C. E., Fuel, 20, 130 (1941).

'Warren, C. N., Z. Anal. Chem., 3, 272 (1864).

"Mixter, W. G., Amer. J. Sci., (3), 4, 90 (1872).

'Sauer, A., Z. Anal. Chem., 12, 32, 178 (1873).

- Marek, J. prak. Chem., (2), 84, 713 (1911).

"Grote, W., and Krekeler, H., Angewandte Chem., 46, 106 (1933).

schöberl, A., Angewandte Chem., 50, 334 (1937).

- ter Meulen, H., and Heslinga, J., "Neue Methoden der OrganischChemischen Analyse", Leipzig, 37 (1927).

\section{Change of Symmetry of Basic Beryllium Acetate}

Preston and Trotter ${ }^{1}$ have described a change of symmetry with temperature in the Laue photographs of basic beryllium acetate, $\mathrm{Be}_{4} \mathrm{O}\left(\mathrm{CH}_{3} \mathrm{COO}\right)_{6}$. This change of symmetry, according to Preston and Trotter, is a reversible one and occurs between $30^{\circ}$ and $50^{\circ} \mathrm{C}$. At the higher temperature the crystal class possesses three-fold axes with parallel mirrorplanes, whereas at the lower temperature only the three-fold axes are present. Preston and Trotter suggest that the increase in symmetry is due to the setting in of molecular vibration of the acetate groups.

We have taken single-crystal photographs of this substance at temperatures between $15^{\circ}$ and $80^{\circ}$, using a special Weissenberg camera. These photographs show the change of symmetry very beautifully. Below $25^{\circ}$ a spot $(h k 0)$ has in general a different intensity of reflexion from $(k h 0)$. As the temperature is raised above $25^{\circ}$, however, a change begins which becomes complete at $40^{\circ}$ whereby the $(h k 0)$ and $(k h 0)$ reflexions become equal in intensity. The change is especially rapid between $37^{\circ}$ and $40^{\circ}$. As found by Preston and Trotter, the change appears to be completely reversible with no hysteresis.

The Weissenberg photographs give the complete set of $(h k 0)$ intensities, and permit the changes in atomic parameters to be followed by Fourier synthesis. The signs of the $F^{\top}$ values are obtainable from the Pauling and Sherman structure ${ }^{2}$. The results of this work enable the following conclusion to be drawn. As the temperature increases from $25^{\circ}$ to $40^{\circ}$, there is a gradual change in the parameters of the carboxyl oxygens from the values $(\overline{0.17} \overline{0.06} \overline{0.04})$ to the values $\overline{(0 \cdot \overline{17}} \overline{0 \cdot 05} \overline{0 \cdot 05})$ respectively. All other atomic parameters remain unchanged. The lowtemperature values $(\overline{0.17} \overline{0.06} \overline{0.04)}$, which correspond, closely to the Pauling and Sherman structure, mean that the oxygens are already within $0.23 \mathrm{~A}$. of the (110) planes, which become the mirror planes at $40^{\circ} \mathrm{C}$. As the temperature is raised above $25^{\circ}$, there is a gradual displacement of all the carboxyl oxygens until at $40^{\circ}$ they lie exactly on the (110) planes.

There is thus no question of the setting in of any abnormal thermal oscillations in this crystal. The effect observed by Preston and Trotter is merely due to a small change in the atomic parameters. The change corresponds to a rotation of the $\mathrm{CH}_{3} \mathrm{COO}$ groups about the line joining the two carbon atoms, and is such as to make yery little alteration in the distances within the molecule. Some of the intermolecular distances (van der Waals' bonds) are modified slightly.

This crystal would seem to permit a very accurate determination to be made of the size of the $-\mathrm{COOH}$ group, and indeed was used for this purpose by Pauling and Sherman. It is not thought that the results derived in the present work by two-dimensional Fourier synthesis are any more accurate than the result obtained by Pauling and Sherman, who used a small number of general intensities. It is thought, however, that the use of three-dimensional Fourier synthesis using all the available general intensities would enable an extremely good determination to be made.

I am indebted to Mr. T. Sheddan for growing the crystals used in this investigation, and for much help in the X-ray photography.

$$
\text { C. A. BeEvers. }
$$

(Dewar Research Fellow.)

Chemistry Department,

University of Edinburgh. Sept. 15.

1 NATURR, 151, 166 (1943).

${ }^{2}$ Proc. U.S. Nat. Acad. Sci., 20, 340 (1934).

\section{Apparent Vitamin $\mathrm{C}$ in Walnuts}

THE remarkably high vitamin $\mathrm{C}$ content of walnuts has been mentioned by various workers ${ }^{1.2}$. Recent work ${ }^{3,4}$ indicates that foods may contain substances which react with the dye and are estimated as ascorbic acid under the usual titration conditions but are not true vitamin C. This apparent vitamin $C$ has now been found in walnuts. Twenty-one samples of five different species have been examined, and all were found to contain considerable amounts of apparent vitamin $\mathrm{C}$ (see accompanying table). The Juglans regia samples were collected in Kew, Long Ashton and Berkhamsted. All the other samples came from Kew. The flowers of many trees of Juglans and Carya were destroyed by frosts, which prevented the investigation of a wider range of species. The material available was further restricted by the depredations of grey squirrels, at present a serious pest at Kew. The nuts ranged in weight from $2 \mathrm{gm}$. to $40 \mathrm{gm}$., and included different stages of ripening up to those in which the shell had becone hard and woody. Thus, apparent vitamin $\mathrm{C}$ should be found in walnuts which are pickled or used in jam-making, etc. Mapson ${ }^{5}$ has found that 14 per cent of the total vitamin $\mathrm{C}$ in some walnuts preserved in syrup was apparent vitamin $\mathrm{C}$.

In our investigation the apparent vitamin $\mathrm{C}$ was estimated by Mapson's visual method and by our own visual and potentiometric methods ${ }^{6}$ on a number of samples. All three methods showed the presence of the apparent vitamin $\mathrm{C}$ and (with certain exceptions to be considered in a later communication) the results by the three methods were in reasonable agreement. The apparent vitamin $\mathrm{C}$ was not due to tannin, since the results were not appreciably 